\title{
Left Upper Limb Loss In A Neonate From Gangrene Secondary To Treatment Of Birth Injury By Traditional Bone Setters (TBS).
}

\author{
Odatuwa -Omagbemi DO ${ }^{1}$, Akpojevwe $\mathrm{E}^{2}$, Otene $\mathrm{CI}^{1}$, Enemudo RET ${ }^{1}$, \\ Dioru $\mathrm{UN}^{2}$, Obumse $\mathrm{A}^{2}$. \\ ${ }^{I}$ Department of Surgery, Delta State University, Abraka. Nigeria \\ ${ }^{2}$ Department of Orthopaedics and Traumatology, Delta State University Teaching Hospital, Oghara. Nigeria.
}

\begin{abstract}
:
Background: Complications arising from treatment of musculoskeletal injuries by traditional bone setters (TBS) are a constant threat to limbs in our environment. Gangrene of usually a part of a limb is one such complications that is not uncommon. However gangrene involving a whole limb in a neonate due to treatment of birth injury by traditional bone setters is not common.

Case Report: A 4 week old female neonate presented to our emergency room with gangrene of the whole of the left upper limb that resulted from treatment of a birth injury by traditional bone setters. She subsequently had an open left shoulder disarticulation after initial resuscitation. She did very well post-operatively and had secondary wound closure four weeks after initial surgery. She was discharged home after 33 days on admission. Conclusion: This is another case of maiming at the very beginning of life due to the activities of unscrupulous traditional bone setters. The need to curtail their activities and punish defaulters cannot be overemphasised.

Keywords: Whole limb gangrene, Traditional bone setters (TBS), neonate, limb loss.
\end{abstract}

\section{Introduction}

Traditional bone setting is an age long practice in Africa and many developing countries. It has its roots in antiquity and like other forms of traditional medicine, predates documented history. It involves manipulation and massaging of sprains, dislocations and fractures in addition to application of concoctions and splints to injured areas. Incantations and other rituals are also performed in some cases to invoke the gods and ancestors for divine assistance and intervention in the healing process [1,2,3].

Patronage is wide spread involving the educated and uneducated, the rich and the poor. Reasons adduced for this popularity include the widespread distribution of the traditional bone setters (TBS) both in rural and urban areas, cheaper services, acceptance of flexible modes of payment including payment in kind, credit facilities and offering of home services. In addition, they are usually also members of the communities where they practice and have gained the confidence of the people over the years. $[4,5,6]$

According to an estimate, 10 to $40 \%$ of patients with fractures in the world are managed by non orthodox practitioners. [7,8]. The practice is very popular in Nigeria where it is estimated that 70 to $90 \%$ of fractures are initially managed by TBS with only the complicated cases eventually getting to the orthodox practitioners. $[3,9,10]$

Their methods of practice which have been severally frothed with unacceptable complications have not changed over the years. Reported complications include: Nonunions, malunions, conversion of closed to open fractures, osteomyelitis, joint stiffness, chronic unreduced dislocations, pressure sores, local sepsis, septicaemia, anaemia, septic arthritis, compartment syndrome, avascular necrosis, iathrogenic fractures, Volkmann's ischaemic contracrures, frank limb gangrene and death. $[2,11,12,13,14,13,15]$ The list is by no means exhaustive.

Aside from death which may arise as the ultimate complication, the most dreaded complication for a live patients is frank limb gangrene which in many cases result from inappropriate application of splints and bandaging. Many times these splints are applied to very minor or insignificant injuries that ordinarily would not have needed more than just rest and analgesics.

We report a case of gangrene of the whole of the left upper due to traditional bone setters' treatment of a birth injury leading to disarticulation of the limb at the level of the left shoulder. 


\section{Case Report}

A twenty eight day old neonate presented to the children emergency room of our health facility (The Delta State University Teaching Hospital, Oghara, Delta State. Nigeria) with a 3 day history of swelling, dark discolouration and loss of sensation in the left upper limb. There was associated 2 days history of fever and foul smelling discharge from the same limb. Child was a product of a spontaneous vertex delivery by a 37 year old mother at term 4 weeks prior to presentation. Delivery was at a peripherial primary health facility. Pregnancy and antenatal periods were said not to be eventful. However, second stage of labour was prolonged and baby was said to have been manually pulled out of the vagina by the midwife after giving an episiotomy. After resuscitation, patient was noticed not to be moving the left upper limb. She was consequently referred to a secondary health facility as a case of birth trauma for expert management. Parents however, opted to take baby for traditional bone setters' (TBS) treatment. She was treated serially by 3 different traditional bone setters who manipulated and applied splints and bandaged the left upper limb. Child was taken to a third TBS when there was no improvement from the treatment given by the first two bone setters. Following application of splint and bandaging by the third TBS, child cried persistently from pain but was ignored as parents were told by the traditional bone setter that the pain signified that healing was taking place. After a period of about 24 to 48 hours the left upper limb was noticed to have turned dark and insensate. Fever developed in the following days with limb exuding a foul smelling discharge. Baby was subsequently brought to our centre after bandage and splints were removed. Examination at presentation revealed an ill looking but conscious neonate, who was febrile with a temperature of $38^{\circ} \mathrm{C}$. She was not pale and not jaundiced. Pulse was $140 /$ minute and respiratory rate was 34 cycles per minute. Essential findings in the musculo-skeletal system was gangrene of the whole of the left upper limb extending up to the left axilla with macerated skin, blisters and foul smell. (figure 1.)

A diagnosis of 'Left Upper Limb Gangrene Secondary to Traditional Bone Setter's Treatment of Birth Injury and Septicaemia' was made. Patient was resuscitated with intravenous fluid, antibiotic, analgesics and antipyretics. She was investigated and worked-up for emergency open left shoulder disarticulation.

The packed cell volume was $32 \%$ with neutrophilia in the differential white cell count. Electrolyte, urea and creatinine values were within normal limits.

Patient had open left shoulder disarticulation about 48 hours after presentation delay being as a result of financial constraints and initial withholding of consent by her father. Under general anaesthesia, incision was made following the line of skin demarcation. Essential intra-operative findings included thrombosed axillary vessels and a sub-capital left femoral fracture. The axillary vessels were ligated proximal to the level of thrombosis, dead tissues removed and wound left open. Blood loss was minimal. Post-operatively, patient continued on antibiotics and wound care. Wound granulated well with dressing and patient had undermining of skin edges, advancement and secondary wound closure 4 weeks after initial surgery. Wound healed well and patient was discharged home after 33 days in the hospital.

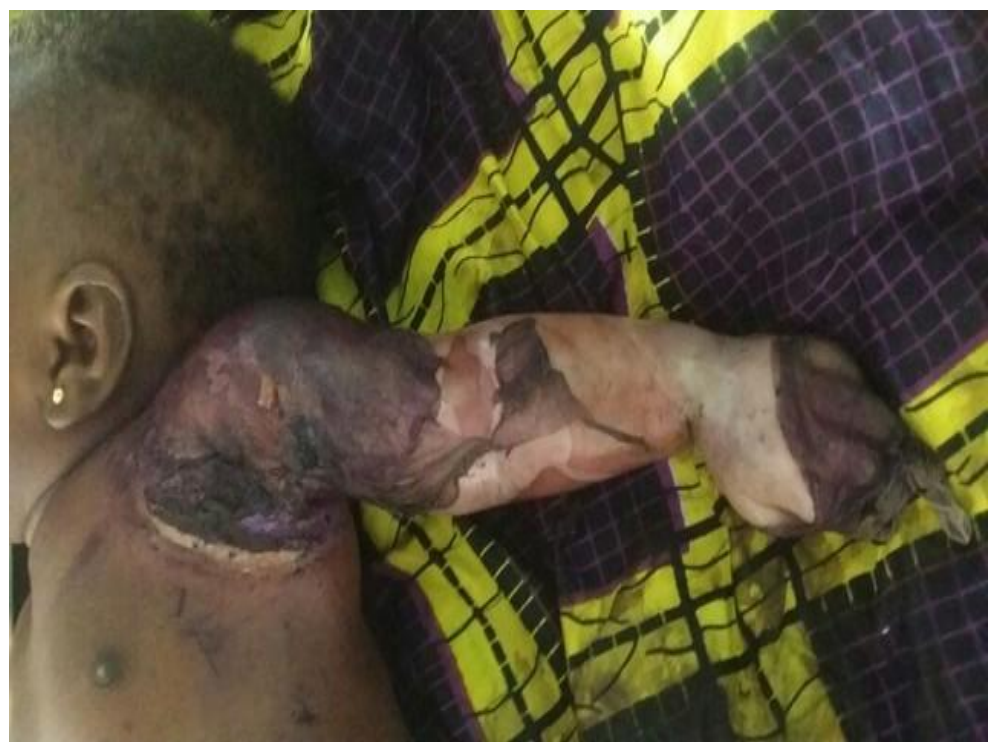

Figure 1. Neonate with Gangrene of the Whole Left Upper Limb at Presentation. 


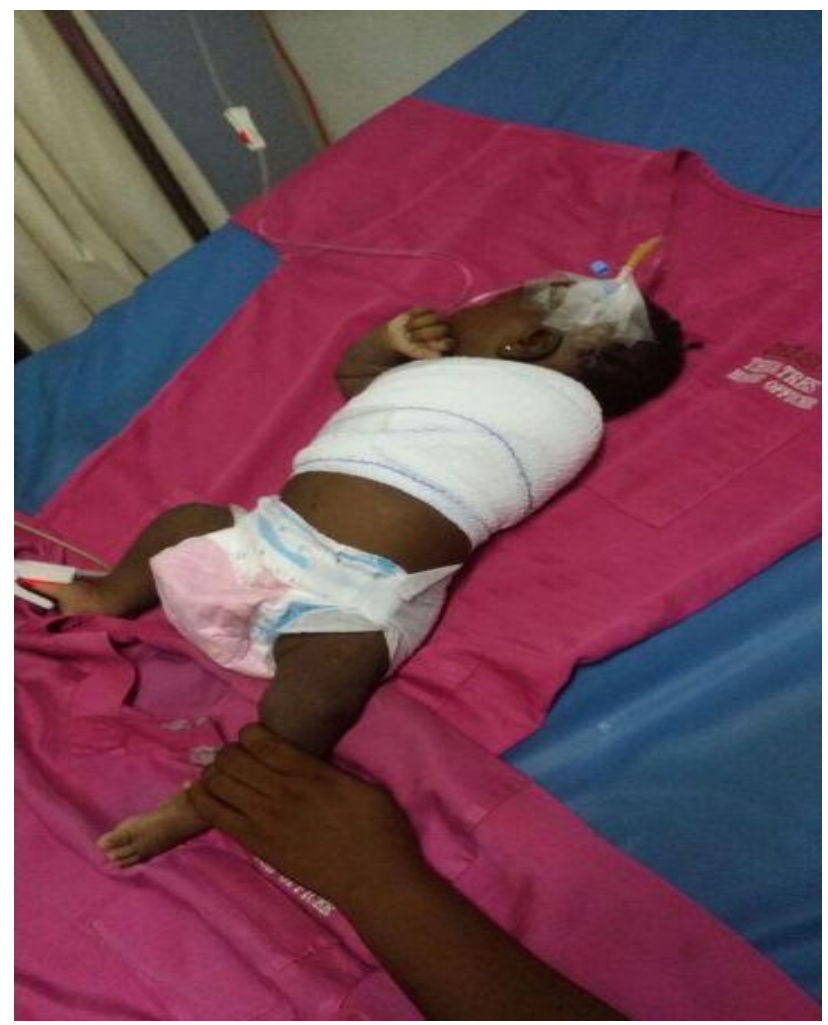

Figure 2. Immediate Post-Operative Photogragh With Dressing On.

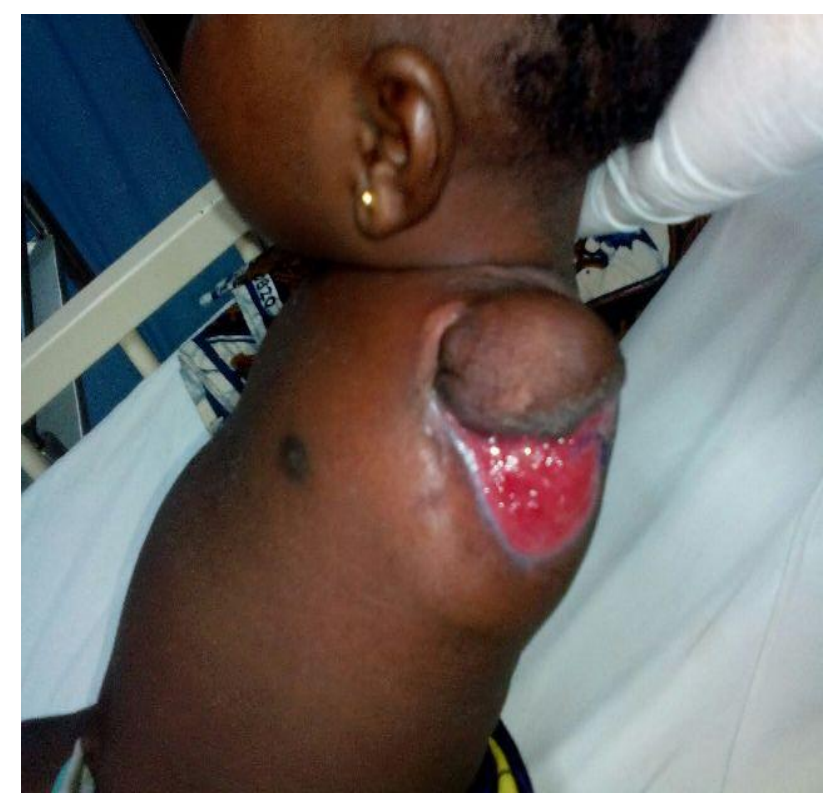

Figure 3. Three weeks post left shoulder disarticulation with wound exposed.

\section{Discussion}

Complications arising from the activities of traditional bone setters who treat musculo-skeletal injuries have been well documental over the years by various authors. $[2,6,12,13,14,16]$. These complications are not rare in our environment. However, this case presents some rare peculiarities.

Firstly, gangrene resulting from treatment of injuries by traditional bone setters usually affect part of a limb and not the whole limb. TBS gangrene affecting the whole upper limb as in this case is uncommon [17].

Another peculiarity of this case is the extremely young age of the victim. At such a tender age (first few days of life) when even orthodox practitioners are wary of the type of treatment given to such babies due to their immature anatomy and physiology, these traditional bone setters still dabbled in to treat not minding the consequences. Ignorance appears to be their greatest problem and they themselves seem not to be aware of this. 
Here lies the enormity of the problem in our hands - since the most difficult group of persons to deal with are those who do not know but think they know or are not aware that they do not know.

Thirdly, birth injuries are not a commonly documented reason for seeking TBS treatment, at least not in the first few days of life. Most parents especially the enlightened ones tend to be a bit more careful at this age about who they take their babies to for treatment. Both parents here were illiterates and not enlightened which probably also explains their careless and carefree behaviour.

The most dreaded of the complications of treatment by traditional bone setters (aside from death) is limb ischaemia and frank gangrene. TBS gangrene tend to occur more frequently in children $[13,18,19,20,21,22]$. According to Akinyoola et al [18], 92.3\% of amputations in children due to trauma in their study were indicated as a result of gangrene resulting from TBS treatment of simple musculoskeletal injuries. The reasons for children being most frequently affected are not farfetched. Children do not make their own decisions and always depend on the decision of adults (parents and guardians) but they bear the consequences of wrong decisions - in this case complications of the decision to go for TBS treatment. In addition children are usually forced to bear the severe ischaemic pains that normally precede limb gangrene on application of tight TBS splints. Their parents most times have been pre-instructed not to remove splints on any account and that pain is usually a sign of the effectiveness of treatment and part of the healing process. By the time they realise their folly, the damage would already have been done. On the contrary adults apart from being responsible for the final decision on whether or not to take treatment from TBS, many times on their own remove tight splints when the ischaemic pain becomes unbearable thus saving their limbs. Our patient was not only a child but a few days old neonate totally at the mercy of the TBS and the parents. The persistent cry from pain due to ischaemia caused by application of tight splint to the injured limb by our patient was as usual ignored by the parents based on the TBS's instruction. It was only when the limb became gangrenous with change in colour, loss of sensation and foul smelling discharge that the parents realised there was a serious problem. This is the usual pathetic story for many children and our patient went through the same pathway. There is need to thus educate both parents and the bone setters of the importance of severe pain as a sign of ischaemia and imminent gangrene and the need to urgently remove splint when this occurs.

Cases of patients leaving orthodox hospitals to seek treatment from TBS have also been variously alluded to. $[9,12,14]$. The parents of our patient left the hospital where child was born with a referral letter to a nearby bigger hospital for the specialist treatment of the birth injury. They however did not go to the destination hospital but instead went to seek treatment from traditional bone setters. The reason given by the parents for this decision was that they lost confidence in orthodox care since the injury occurred there in the first instance. They also in addition believed that traditional bone setters were better at treatment of musculoskeletal injuries hence they went through 3 consecutive bone setters seeking treatment. Gangrene occurred while patient was receiving treatment from the third bone setter. This strong belief by our people in the ability of TBS to better treat musculoskeletal injuries have also been variously reported in the literature. $[4,6,9,16,18]$.

The use of splinters made from various materials (bamboo, tree barks, etc) which are firmly bandage to injury sites after application of some herbal mixtures is the major method of treatment by many bone setters in Africa. [3,9,10,14,18,19]. The amount of pressure applied to the splints while bandaging usually determines whether the limb develops compartment syndrome, Volkmann's ichaemic contracture, frank gangrene or escapes without any of these complications. From all evidences, the pressure applied is not gauged in any way hence the lucky ones escape these complications. Our patient was probably lucky to have escaped in the hands of the first 2 bone setters who also applied splints. She was however, not that fortunate with the $3^{\text {rd }}$ one whose splint resulted in the gangrene of the injured limb. This explanation agrees with several other reports in the literature. $[3,9,15,19,20,23]$.

The issue of low socio-economic class is also said to play some role in determining the patronage of traditional bone setters by patients. Among the reasons adduced for TBS patronage are that the cost of treatment is cheap and mode of payment is flexible. [4,6,5,13]. Kuubiere et al [14] reported that persons of low socioeconomic class tend to patronise traditional bone setters than others. The parents of our patient happen to be of low socioeconomic class. The delay in amputation was majorly caused by initial inability to pay for surgery even after consent was given by the child's father. This also affected subsequent management of this patient.

The amputation (disarticulation) carried out in our patient was done in 2 stages due to infection and the proximal nature of the gangrene (shoulder level). This is a common operative decision in many cases of TBS gangrene who often present with ascending infections necessitating initial open procedures and definitive wound closure at a later date. [19].

In conclusion, this case has opened our eyes once more to the menace of traditional bone setters' activities and the dangers inherent in their practice. This child will never be able to appreciate for the rest her life what it feels like to have two upper limbs. She obviously will function like a child with incomplete amelia in this case, 'acquired'. It is disheartening that this happens while the unscrupulous perpetrators of this heinous 
crime walk freely around making bogus claims of their medical prowess and successes in the media unrestricted and hunting for the next unfortunate victim. They definitely need to be punished and their activities curtailed to stop or at least reduce the extent of the danger they pose. All stake holders including orthodox medical practitioners, the public and government need to come together to find a lasting solution to this problem that appears to be getting worse. Various suggestions including public enlightenment, registration and training / licensing of bone setters, enactment of laws restricting TBS practice and spelling out punishment for malpractice etc have been proposed as way forward in the past $[2,3,9,10,18,20]$. There is need for government to harmonise these views and take definite actions to arrest this ugly situation.

\section{References.}

[1]. Kwaja CMA. Setting the Bones of Traditional Bone Setting: Wonder Cures. West African Insight. 2011; Available from: www.westafricaninsight.org/articles/PDF/144

[2]. Odatuwa-Omagbemi DO. Complications of Traditional Bone Setters Practice in Nigeria: The Need for Urgent Action. Nig Research Clin Sci. 2012(April); 2(1): 1-5.

[3]. Odatuwa-Omagbemi DO, Enemudo RET, Enamine SE, Esezobor EE. Traditional Bone Setting in the Niger Delta region of Nigeria. Nig J Med. 2014. ; 23 (2): 157-161.

[4]. Thanni LOA. Factors Influencing Patronage of Traditional Bone Setters. West Afr J Med. 2000; 19(3): 220-224.

[5]. Aderibigbe SA, Agaja SR, Bamidele JO. Determinants of Utilisation of Traditional Bone Setters in Ilorin. Journal of Preventive Medicine and Hygiene. 2013; 54: 35-40.

[6]. Dada AA, Yinusa W, Giwa SO. Review of Practice of Traditional Bone Setting in Nigeria. Afr Health Sci. 2011; 11(2): 262-265.

[7]. Agarwal MS, Agarwal MD. The Practice and Tradition of Bone Setting. Education for Health. 2010; 1(23). Available from: http://www.educationforhealth.net

[8]. Green SA. Orthopaedic Surgeons: Inheritors of Tradition. Clin Orthop Relat Res. 1999; 363: 258-263.

[9]. Omololu AB, Ogunlade SO, Gopaldesoni VK. The Practice of Traditional Bone Setting: Training Algorithm. Clin Orthop. 2008; 466(10): 2392-2398.

[10]. Nwachukwu BU, Okwesili CI, Harris HB, Katz JN. Traditional Bone Setters and Contemporary Orthopaedic Fracture Carei n a Developing Nation: Historical Aspect, Contemporary Status and Future Direction. The Open Orthop J. 2011: 20-26.

[11]. Ogunlusi OO, Oginni LM, Oyedeji OA, Ibigbami O. Acquired Boneless Forearm as a Complication of Traditional Bone Setting. Orthopaedics. 2008; 31(3): 288.

[12]. OlaOlorun DA, Oludiran IO, Adeniran A. Complications of Fracture Treatment by Traditional Bone Setters in South Western Nigeria. Family Practice. 2001; 18(6): 635-637.

[13]. El Hag MIA, El Hag OBM. Complications in Fractures Treated by Traditional Bone Setters in Khartoum. Khartoum Med. J. 2010; 03(1): 401-405.

[14]. Kuubiere BC, Abass A, Mustapha I. Fracture Complications after Treatment by Traditional Bone Setters in Northern Ghana. Adv Appl Sci Res. 2013; 4(6): 207-211.

[15]. Onyemaechi NOC, Onwuasoigwe O, Nwankwo OE, Schuh A, Popoola SO. Complications of Musculoskeletal Injuries Treated by Traditional Bone Setters in a Developing Country. Indian Journal of Applied Research. 2014; 4(3): 313-316.

[16]. Alonge TO, Dongo AE, Notidge TE, Omololu AB, Ogunlade SO. Traditional Bone Setters in South West Nigeria: Friends or Foes. West Afr J Med. 2004; 23(1): 81-84.

[17]. Kadir DM, Jimoh OR, Kadir RE. Upper Limb Gangrene from Axillary Artery Ligation. Journal of Case Reports. 2016; 6(3): 415419.

[18]. Akinyoola AL, Oginni LM, Adegbehingbe OO, Orimolade EA, Ogundele OJ. Causes of Limb Amputations in Nigeria. West Afr J Med. 2006; 25(4): 273-275.

[19]. Umaru RH, Gali BM, Ali N. Role of Inappropriate Traditional Splintage in Limb Amptutations in Maiduguri, Nigeria. Annals Afr Med. 2004; 3(3): 138-140.

[20]. Nwandiaro HC, Kidmas AT, Ozoilo KN. Outcome of Traditional Bone Setting in the Middle Belt of Nigeria. Nig J Surg Res. 2006; $8(1-2): 44-48$.

[21]. Nwandiaro HC, Liman HU, Onu MI, Ozoilo KN. Presentation of Complications among Orthopaedic Patients. Nig J Surg Sci 1999; 9: 34-37.

[22]. Bickler SW, Sanno-Dauda D. Bone Setters Gangrene. Paedr Surg. 2000; 35: 1431 - 1433.

[23]. Yakubu A, Muhammad IH, Mabogunje O. Limb Amputation in Children in Zaria, Nigeria. Annals of Tropical Paediatrics and International Child Health. 1995; 15(2): 163 - 165. 